\title{
Una aproximación a la minería y la metalurgia andalusí en la depresión de Vera (Almería)
}

\author{
Montserrat Menasanch de Tobaruela*
}

\section{LA ZONA DE ESTUDIO}

La denominada depresión de Vera se encuentra situada en el extremo nororiental de la provincia de Almería, unos $50 \mathrm{~km}$. al Sur de Lorca. Se trata de una cuenca terciaria de alrededor de $320 \mathrm{~km}^{2}$ de superficie, atravesada por los valles de los ríos Almanzora, Antas y Aguas y rodeada por las sierras de Almagro y Almagrera al Norte, de Bédar y Lisbona al Oeste, y Cabrera al Sur. Por el Este, la cuenca se abre al Mediterráneo (f.I). El mar constituye su principal vía de comunicación, mientras que por tierra se encuentra conectada sobre todo con el valle del Guadalentín a través del campo de Pulpí.

Como han mostrado los estudios paleoecológicos (CASTRO et al., 1994; CASTRO et al., 1998), la actual degración del medio no es resultado sólo de la interacción socionatural contemporánea, sino de sucesivos momentos de explotación masiva desde la prehistoria reciente hasta el auge minero de finales del siglo XIX y principios del $X X$.

Precisamente este auge da cuenta del interés de la zona desde el punto de vista de los recursos minerales. Sin entrar a profundizar en la naturaleza y distribución de los criaderos, nos limitaremos a señalar la existencia de minas de distintos minerales sobre todo en los aflo- ramientos preneógenos que bordean la depresión (IGME, 198I). Así, minerales como la azurita y la malaquita se encuentran en las sierras Cabrera y de Almagro, respectivamente en los extremos meridional y septentrional de la cuenca y, sobre todo, algo más al Norte, en el llamado Cerro Minado de Huércal Overa. La galena se puede extraer de las dos sierras mencionadas, y también de sierra Almagrera y del yacimiento de Herrerías (Cuevas del Almanzora), uno de los más intensamente explotados en distintos periodos históricos, rico sobre todo en mineral de plata. $Y$ minerales de hierro como hematita, siderita, pirita o limonita abundan en la sierra de Bédar y están presentes en la sierra de Almagro y en la mencionada Herrerías.

Estas son las minas cartografiadas en el mapa metalogenético. Sin embargo, en los bordes montañosos existen otros afloramientos, a veces superficiales, que hoy no se considerarían rentables, pero que pudieron ser objeto de explotación en el pasado. Concretamente, en sierra Cabrera, donde se realizó una prospección pormenorizada de estos recursos en torno al asentamiento de Gatas (Turre) (CARULLA, 1987), se detectó la existencia de afloramientos de menas metálicas con leyes de hierro que alcanzan el $56.7 \%$, y en el propio cerro de Gatas se constató la presencia en superficie de carbonatos de este metal con una ley del $36.2 \%$. 


\section{ALGUNOS INDICIOS DE EXPLOTACION ANTIGUA}

Así pues, los yacimientos mineros de la depresión de Vera ofrecen recursos para la obtención de distintos metales, concretamente cobre, plomo, plata y hierro. Los textos y la documentación arqueológica de principios de siglo proporcionan algunos indicios del interés que éstos despertaron en las comunidades andalusíes.

En un reciente trabajo sobre minería en la Almería islámica, Cressier (1998) recopila una serie de fuentes árabes que hacen referencia de forma más o menos general a la riqueza metalífera de la actual provincia !. Básicamente, las noticias consisten en menciones a la existencia de determinados metales en distintas zonas geográficas y a la elaboración de manufacturas de cobre y de hierro en Almería.

Según estas fuentes, en el siglo IX se explotaban minas de plata, y desde el siglo $X$ se conocían y probablemente se trabajaban minas de oro, plata, plomo, cobre y hierro. En cuanto a las áreas de localización de los yacimientos, se identifican las sierras de Gádor, Alhamilla, Filabres, y quizá sierra Almagrera.

Por lo que respecta a nuestra área de estudio, no conocemos ninguna noticia directa transmitida por los textos árabes relativa a la minería. En el siglo Xl, al-'Uḍī relata que casi dos siglos antes, a finales del IX, el muladí Daysan Ibn Ishaq se levantó contra el emirato cordobés, apoderándose de las minas de plata de la cora de Tudmir (TAPIA, 1986: 88 ss.), y que los criaderos producían "mil cargas de caballería" de plomo para el rebelde (CRESSIER, 1998). Tapia identifica estos yacimientos de mineral con los de sierra Almagrera, en la depresión de Vera, mientras que Cressier considera verosímil que se trate de éstos, si bien señala como otra posibilidad las minas de Cartagena.

Menos indirecta es la documentación inmediatamente posterior a la conquista, en la que se registran varios permisos concedidos para la explotación de yacimientos de mineral. Así, en 151 I el repartidor Diego López de Haro recibe en merced de la reina doña Juana el derecho a explotar todas las minas de hierro, conocidas o no, de sierra Cabrera, y a instalar herrerías (GRIMA, 1987: p. 169). Del mismo modo, en 1525 se conceden mercedes y permisos a L. Galíndez Carvajal para la explotación principalmente de hierro en la sierra de Bédar, y al duque de Alba para minas no especificadas de la jurisdicción de Vera (CARA BARRIONUEVO y RODRÍGUEZ LÓPEZ, 1986).

Como indica Cressier (1998), de estos datos no se puede concluir directamente la práctica de la minería en momentos anteriores, aunque sí permiten plantear su existencia. En este sentido se puede interpretar el permiso a López de Haro para explotar tanto las minas conocidas como otras nuevas.

Hasta aquí la información disponible proporcionada por los textos. A ella podemos añadir la recogida por $L$. Siret, ingeniero belga que trabajó largo tiempo en las explotaciones mineras de la depresión durante los años de extracción masiva. En su trabajo sobre Villaricos y Herrerías (SIRET, 1906) da a conocer una serie de hallazgos que ponen de manifiesto que, en el pasado, se practicaron intensamente la minería y la metalurgia de la plata y el plomo en la zona de Herrerías y sierra Almagrera. Sin embargo, sólo algunos de estos restos se pueden atribuir con fiabilidad a un periodo concreto. Como dato cronológico definido, el autor menciona que en una galería antigua de la mina Petronila, en el Cerro Virtud (Herrerías), se encontró una caja de madera cosida con esparto en cuyo interior aparecieron algunas monedas de plata "árabes", que no reproduce (SIRET, 1906: pp. 44, 73). Siret lo interpreta como una ocultación posterior al abandono de la labor antigua, si bien hay que tener en cuenta que el hallazgo marca el terminus ante quem para el abandono, y por lo tanto, que la mina, o la galería, pudieron seguir explotadas hasta el mismo periodo andalusí.

I. Los autores citados por Cressier son los siguientes: al-Razī, al-Bakrī, al-Himyarī, Watwāt, al-Maqqarī, al-Udrī, al-ldrīsī, 'Abd al-Waḥid y al-Marrakušì. Asimismo, se cita la Descripción anónima de al-Andalus. 


\section{EL REGISTRO ARQUEOLÓGICO RECIENTE}

Pero no ha sido hasta las últimas décadas que hemos empezado a disponer de evidencias materiales de que las comunidades andalusíes asentadas en la depresión de Vera desarrollaron actividades relacionadas con la minería y la metalurgia.

Las más notables se han registrado en el yacimiento de El Argar, conocido sobre todo por el grupo arqueológico al que da nombre, y en el que una serie de sondeos estratigráficos pusieron de manifiesto la existencia de una reocupación en el periodo medieval (SCHUBART, 1993).

El yacimiento se encuentra situado en la zona central de la depresión, sobre una terraza fluvial junto a la margen izquierda del río Antas (f. I). En el trabajo de los hermanos Siret sobre la prehistoria reciente del Sudeste (SIRET y SIRET, 1890: Im. 23.82, 85, 96 y Im. 25.36-37) ya se registran algunos indicios de la presencia en el sitio de un asentamiento andalusí. Entre los materiales publicados figuran, entre otros, un fragmento de jarrita con asa sobreelevada cuyas características morfológicas recuerdan a ejemplares del nivel inferior de Pechina (CASTILLO GALDEANO y MARTINEZ MADRID, 1993) y del testar del alfar antiguo de San Nicolás, en Murcia (NAVARRO PALAZON, 1990), una pared de un recipiente indeterminado con cordón aplicado e impreso y varias agujas o alfileres de latón.

Las excavaciones realizadas hace algunos años descubrieron varias estructuras pertenecientes a este asentamiento (SCHUBART, 1993). Se trata de una serie de habitaciones de planta cuadrangular con zócalo de piedra, una de las cuales contaba con una superficie de trabajo también de piedra. En la construcción de algunos de los muros se utilizó un aparejo en espiga igual al empleado en algunas de las estructuras del asentamiento andalusí de Gatas (FERNÁNDEZ UGALDE et al., 1999).

La reocupación de El Argar se ha fechado en el periodo comprendido entre los siglos VIII-X por la presencia, entre el repertorio de cerámica medieval, de fondos planos y convexos, la ausencia de soleros, de cuerda seca y de verde y manganeso, y por los escasos vidriados monocromos (POZO MARÍN y RUEDA CRUZ, 1993). Sin embargo, determinadas características del material y del contexto regional del yacimiento nos inclinan a pensar que la vida del poblado se pudo prolongar hasta un momento posterior, al menos durante el siglo $X^{2}$.

En relación al tema que nos ocupa, en dos de los tres sondeos excavados (sondeos I y 3), distantes entre sí unos $60 \mathrm{~m}$, se detectó la presencia de escoria derivada de la fundición de mineral de hierro. En el sondeo I ésta apareció en gran cantidad bajo la superficie de trabajo a la que nos hemos referido, mientras que en el sondeo 3, "a poca profundidad bajo el nivel superficial", se encontró una goa de II $\mathrm{kg}$ de peso (SCHUBART, 1993).

Por el momento no conocemos otros detalles acerca de la composición del poblado, de su organización urbanística o de posibles áreas funcionales. Lo que sí podemos plantear es que se trata de un núcleo aparentemente especializado en la metalurgia del hierro, con un volumen de producción notable. Con los datos disponibles resulta difícil situar las actividades metalúrgicas en un momento concreto. Con-

\footnotetext{
2. En relación a la temporalidad que tiende a situar el sitio en un momento temprano, es posible hacer algunas observaciones. En primer lugar, para el siglo VIII en el Sudeste se carece de estratigrafías, y aún más de indicadores cronológicos absolutos, ya sean contextuales (aquellos que forman parte física de los contextos estratigráficos) o textuales (documentos que contienen fechas referentes a un espacio concreto, pero que no guardan relación física con éste). Por otra parte, si bien los ataifores de fondo plano o convexo aparecen en varios yacimientos en niveles fechados como emirales (ACIÉN ALMANSA y MARTÍNEZ MADRID, I989; ACIÉN et al., 1995), también se encuentran en Ilbīra (CANO PIEDRA, 1990), y son el tipo más frecuente en Madīnat al-Zahrā' (ESCUDERO ARANDA, 1988-90). En cuanto a la ausencia de determinadas formas o técnicas -en este caso la cuerda seca y el verde y manganeso-, puede tener un significado distinto del cronológico, máxime si tenemos en cuenta que nos encontramos en un contexto rural, y que tanto una como la otra son muy escasas en la depresión, donde hasta el momento sólo conocemos dos fragmentos de verde y manganeso, dos o quizá tres de cuerda seca parcial y uno de cuerda seca total. En consecuencia, consideramos que, si bien la reocupación andalusí de El Argar pudo tener un origen temprano, ésta se debió prolongar en momentos posteriores, quizá incluso más allá de los límites del siglo $X$.
} 
sideramos que éstas pudieron comenzar en la fase emiral y continuar durante el siglo $X$.

Las excavaciones en el yacimiento argárico y postargárico de Fuente Álamo (Cuevas del Almanzora) registraron también la existencia de fases posteriores. Del nivel superficial y de los rellenos más recientes de la antigua cisterna argárica procede un conjunto de materiales andalusíes que no se pudieron asociar a estructuras arquitectónicas (CRESSIER et al., en prensa), probablemente desaparecidas a causa de la erosión. Su estudio permitió reconocer que el sitio estuvo poblado por una comunidad rural durante el periodo emiral y no más allá del primer cuarto del siglo X. Los autores sugieren que una de las actividades productivas de la comunidad pudo ser la minería (CRESSIER et al., en prensa). En efecto, el emplazamiento del sitio, a $1.2 \mathrm{~km}$. de yacimientos de minas de hierro y a unos $3 \mathrm{~km}$. de plata y cobre ${ }^{3}$, resultaría favorable para dicha explotación.

Otro yacimiento probablemente vinculado a la extracción de mineral es el de Cerro Virtud, en Herrerías. La elevación se encuentra situada en el tercio Norte de la depresión, junto al curso bajo del río Almanzora (f. I). Sus filones son particularmente ricos en galena argentífera, aunque también es posible la explotación de hierro.

Durante los trabajos de excavación llevados a cabo recientemente bajo la dirección de I. Montero, se identificó un conjunto de material cerámico andalusí que nos permite ampliar las noticias proporcionadas por Siret (1906) acerca de la frecuentación del sitio en el periodo medieval.

El material procede del corte abierto en la ladera occidental (Sector A). En él se identificó una serie de contextos que no se pudo asociar a restos de estructuras arquitectónicas. El análisis estratigráfico, tafonómico y cronoló- gico mostró que se trataba de depósitos de origen reciente, probablemente formados a consecuencia de la alteración natural o antrópica de contextos anteriores, que contenían material redepositado. Por lo tanto, su presencia se puede considerar indicio de la ocupación o frecuentación de otras zonas del promontorio en distintos periodos históricos, y en concreto, en el andalusí.

De acuerdo con las indicaciones extraídas de los restos cerámicos, las actividades medievales se pueden situar en dos momentos diferenciados. Por una parte, la presencia de la técnica de verde y manganeso, representada por un fragmento de fondo de ataifor con repié anular bajo, nos remite a una temporalidad que se prolonga desde la segunda mitad del siglo $X Y$ a lo largo del siglo XI. Por otra, un grupo formado por fragmentos de ataifor de borde triangular y perfil curvo con vedrío interior blancoturquesa, o verde al interior y melado al exterior, un fragmento de jarrita pajiza con profusa decoración pintada al manganeso, un fondo convexo y ligeramente atalonado, también de jarrita, y un fondo con repié de doble anillo separado por acanaladura y vedrío interior se puede situar globalmente en los siglos XIII-XIV, sin descartar una perduración hasta el siglo $X V^{4}$.

Por lo tanto, la información obtenida en la excavación en Cerro Virtud indica la ocupación o frecuentación del sitio en los periodos califal-taifa y nazarí. Dado que disponemos exclusivamente de fragmentos cerámicos redepositados, para proponer la actividad desarrollada en él en esos momentos tenemos que contar con las propias características del sitio, asumiendo su explotación minera.

Por último, los trabajos de prospección superficial realizados en la última década han dado a conocer una serie de asentamientos de diverso carácter en una buena parte de los cuales se registró la presencia de mineral y/o

\footnotetext{
3 Los datos ecológicos proceden de los recopilados en el marco del Proyecto Archaeomedes (CASTRO et al., I994). Agradecemos al equipo redactor el habérnoslos facilitado.

4. Para la ubicación en el tiempo de estas formas se han tomado como referencia materiales procedentes de excavaciones en los cascos urbanos de Murcia y Lorca (NAVARRO PALAZÓN, I986; BERNABE GUILLAMÓN y LÓPEZ MARTíNEZ, I993), así como piezas del Cerro del Castillo, en Albox (MUÑOZ MARTíN y DOMÍNGUEZ BEDMAR, 1984) y de Almería (ALMERÍA, I993).
} 
de escoria de fundición ${ }^{5}$. Algunos son exclusivamente andalusíes, con una o varias fases de ocupación, mientras que otros estuvieron poblados también en periodos anteriores. Por lo tanto, en los casos con varias fases se plantea la cuestión de a qué momento atribuir estos indicios.

Considerando los yacimientos con una sola fase de ocupación, se ha observado que la escoria aparece siempre, bien en asentamientos exclusivamente romanos (siglos III-IV o anteriores), bien en asentamientos exclusivamente andalusíes (siglo IX o posteriores), mientras que está ausente de los sitios que sólo se pueden situar en los siglos $V$ a VIII. Esto nos permite plantear que las actividades minero-metalúrgicas estarían generalizadas en los dos primeros periodos, pero no en el intermedio 6. Así, los yacimientos con fases romana, "tardoantigua" y andalusí no se han tomado en consideración, mientras que en aquellos cuya temporalidad se inicia entre los siglos $\vee$ y VIIVIII y continúa en el IX o posterior, la escoria y/o el mineral se han atribuido a la ocupación andalusí. En todo caso, tratándose de hallazgos de superficie, lo que aquí presentamos se debe considerar una aproximación a la cuestión que se podría ver modificada con la realización de excavaciones en los yacimientos de que se trata.

Con respecto al metal elaborado, los datos de El Argar, así como el análisis de una de las muestras de mineral tomadas en la prospección (infra), apuntan a la metalurgia del hierro, lo cual no excluye que se pudiesen explotar también otros metales.

\section{MINERÍA Y METALURGIA ANDALUSí EN LA DEPRESIÓN DE VERA}

\section{Los inicios}

El momento islámico más temprano apenas se encuentra representado en la depresión de Vera, y de hecho parece que las últimas décadas del siglo VII y el siglo VIII fueron una fase de regresión poblacional durante la cual quedó abandonada buena parte de los núcleos de habitación (MENASANCH, en prensa). La tendencia comienza a cambiar en el siglo IX, cuando se fundan nuevos asentamientos y probablemente se establece el núcleo de Bayra, capital del iqlim del mismo nombre, en el que, según noticia de al-'Udrī, en 868 se terminó de construir la mezquita aljama (MOLINA, 1972: ${ }_{74}{ }^{7}$. Es entonces cuando se registran también los restos más antiguos de minería y fundición andalusíes.

El mineral y la escoria que atestiguan estas actividades aparecen en asentamientos de la zona llana central (El Argar, El Cajete, Pago de San Antón II) y de Sierra Cabrera (Cerro del Picacho), en el tercio meridional. A ellos posiblemente se pueda añadir el mencionado poblado de Fuente Álamo, en el borde montañoso septentrional que forma la Sierra de Almagro (f. I).

Como hemos expuesto, la probabilidad apunta a que en el periodo comprendido entre el siglo $V$ y los siglos VII-VIII la minería y la metalurgia no se desarrollasen de forma generalizada, en la depresión. A juzgar por la toponimia moderna y actual de la zona, la macro-

\footnotetext{
5. En el texto se manejan datos procedentes de prospecciones superficiales llevadas a cabo en la depresión de Vera por el grupo de trabajo de la Universidad Complutense de Madrid, con M. Fernández-Miranda como director, el equipo responsable del proyecto Gatas y los proyectos Archaeomedes y Aguas de la Universidad Autónoma de Barcelona, AREA Sociedad Cooperativa Arqueológica de Madrid y la Universidad de Alcalá de Henares con L. Olmo Enciso y la autora como directores, y la Universidad de Almería, en un proyecto de investigación del bajo Almanzora dirigido por J.L. López Castro. Gracias a la amabilidad del equipo director hemos tenido acceso a los datos obtenidos en la excavación del yacimiento de Gatas (Turre), mientras que el Dr. I. Montero ha proporcionado los datos procedentes de la excavación dirigida por él en Cerro Virtud (Herrerías). Los periodos tardorromano y medieval se encuentran en estudio. Se han dado a conocer avances de los resultados en Menasanch de Tobaruela y Olmo Enciso (I99| y 1994), Fernández Ugalde et al. (1999) y Menasanch de Tobaruela (en prensa).

6. La presencia de escoria y mineral en los yacimientos de Cabecico de Parra y Cerro de Montroy indica que, entre los siglos $V$ y VIIVIII, la situación en la desembocadura del Almanzora pudo ser diferente a la del resto de la depresión.

7. El vaciado de las fuentes escritas, así como el análisis de la toponimia, ha sido realizado por A. Fernández Ugalde, a quien agradecemos su valiosa aportación.
} 
toponimia es eminentemente de origen latinomozárabe, y faltan por completo los topónimos clánicos en Banu-, lo que sugiere que el componente autóctono pudo representar una parte importante de la población de la zona, al menos en los primeros momentos tras la conquista islámica. En este sentido es interesante observar que de diez sitios registrados con fase emiral, siete se encontraban ocupados ya en momentos anteriores.

Sin embargo, sólo en uno de estos asentamientos con continuidad de ocupación (Cerro del Picacho) se identificó la presencia de escoria. Por el contrario, la mayoría de los asentamientos del siglo IX con escoria y/o con emplazamientos favorables para la explotación minera (El Argar, El Cajete, Fuente Alamo y, posiblemente, Pago de San Antón $\|{ }^{8}$ ) son de nueva fundación. Precisamente en dos de ellos (El Argar y Fuente Álamo) aparecen los primeros recipientes vidriados que llegan a la zona de estudio.

Todo esto apunta a que, tras los siglos "tardoantiguos", la producción minero-metalúrgica experimentó importantes cambios en el siglo IX a raíz del contacto, o posiblemente de la presencia -dada la mencionada cita a la mezquita de Bayra y el carácter nuevo de la mayoría de los núcleos fundidores- de nuevas poblaciones en la depresión de Vera.

Los asentamientos en los que ahora se desarrollan actividades metalúrgicas presentan características diferentes entre sí, sobre todo en función de su emplazamiento topográfico. El Argar, El Cajete y Pago de San Antón II son núcleos de llanura, abiertos, con superficies estimadas inferiores a $1 \mathrm{Ha}{ }^{9}$, excepto quizá en el caso del primero. En cuanto al Cerro del Picacho, se trata también de un yacimiento con una superficie máxima de I Ha, sin restos de estructuras de fortificación, aunque en este caso emplazado sobre un cerro escarpado de Sierra Cabrera.
Esta diferencia topográfica supone también ubicaciones desigualmente favorables en cuanto al acceso a los recursos de mineral (tabla I). Así, mientras que el Picacho se sitúa a unos 4 $\mathrm{km}$. de minas de hierro, El Argar, El Cajete y Pago de San Antón II distan más de 6.5 km. de las fuentes de este mismo metal más próximas.

\begin{tabular}{l|c|c|c} 
Yacimiento & Escoria & Mineral & Km. mineral \\
\hline Cerro Montroy & & & $>5 \mathrm{Fe}$ \\
\hline Cortijo Cadímar & $(x)$ & & $\leq 5 \mathrm{Fe}$ \\
\hline El Argar & $\times$ & & $>5 \mathrm{Fe}$ \\
\hline El Cajete & $\times$ & $\mathrm{Fe}$ & $>5 \mathrm{Fe}$ \\
\hline El Picacho & $\times$ & & $\leq 5 \mathrm{Fe}$ \\
\hline Fuente Álamo & & & $\leq 5 \mathrm{Fe}$ \\
\hline Las Zorreras & & & $>5 \mathrm{Fe}$ \\
\hline Loma Rutilla & $(x)$ & & $>5 \mathrm{Fe}$ \\
\hline Pago S. Antón & $(x)$ & & $>5 \mathrm{Fe}$ \\
\hline Pago S. Antón II & $\times$ & & $>5 \mathrm{Fe}$
\end{tabular}

Tabla I: Presencia de escoria y mineral y distancia a fuentes de materia prima de los asentamientos con fase del siglo IX. Los paréntesis indican yacimientos en los que los restos pueden corresponder a distintas fases de ocupación.

De hecho, si consideramos la depresión en su conjunto, una ubicación en el valle del Antas supone las mayores distancias de aprovisionamiento para un sitio que necesite abastecerse de mineral, si bien también es cierto que los asentamientos de la zona central se encuentran aproximadamente equidistantes de los bordes montañosos y de sus respectivos yacimientos mineros.

El Picacho y Pago de San Antón II parecen pequeños asentamientos rurales de distinto carácter -un núcleo "encaramado" y quizá una alquería-, que simultanearían el tratamiento del mineral con otras actividades productivas. En cambio, El Argar e, inmeditamente al Noroeste, El Cajete, representan un conjunto aparentemente especializado en la metalurgia del hierro. El hecho de que este conjunto se encuentre

8. En este asentamiento se documentan formas a mano o a torneta como la olla troncocónica o la tapadera plana tipos M2 y M30.I de Gutiérrez Lloret (1996: 73 ss.), fabricadas con pastas diferentes de los recipientes de sitios de los siglos V-VII, y, en cambio, iguales o muy similares a las de ejemplares, también a mano o a torneta, de los poblados andalusíes de Gatas y El Argar.

9. La estimación del área de los yacimientos se ha basado en el tamaño de las concentraciones de material arqueológico en superficie. Esta medida se ha considerado indicativa del tamaño de los asentamientos. 
relativamente alejado de las minas sugiere que su producción no iría destinada exclusivamente al autoconsumo, y que en la elección del emplazamiento pesaron otras consideraciones.

De las tres cuencas fluviales de la depresión, la del Antas es la que posee la superficie de captación hídrica más reducida $\left(261 \mathrm{~km}^{2}\right.$ fren-

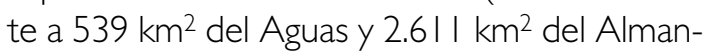
zora) (HOFFMAN, 1988: pp. 29 ss.). Además, desde el punto de vista geológico, en la zona central dominan las extensiones terciarias, aptas para cultivos con menores exigencias hídricas, de los que tenemos menciones en los textos 10. En consecuencia, en esta zona cabe esperar una productividad agrícola menor que, por ejemplo, en Sierra Cabrera, lo que sugiere que tampoco la primacía de la producción subsistencial estaría en la base de la determinación del emplazamiento.

En este punto nos encontramos con la cuestión de la ubicación original de la Bayra mencionada en los textos (ABD AL-KARIM, 1974: pp. |38-139; IDRISI, 1974: pp. 184, I88; MOLINA, 1972). Sin entrar aquí a examinar las propuestas acerca de la misma (véase, por ejemplo, TAPIA 1986 y 1987; CARA y ORTIZ, 1997), nos limitaremos a exponer que los datos de excavaciones recientes en el Cerro de Montroy (Villaricos) (MENASANCH y OLMO, 1991) y los de prospecciones en la zona costera de Villaricos y en los sitios de Pago de San Antón y Cerro del Espíritu Santo (FERNANDEZ UGALDE et al., 1999) permiten plantear que la Bayra de los siglos IX-X se encontraría situada al interior, cerca de la actual Vera, y no junto a la costa, en el solar o las proximidades de la Baria romana. Si esto es así, El Argar-El Cajete distarían unos 4 km. de Bayra, y uno de los factores considerados en la elección de su emplazamiento pudo ser precisamente esta proximidad.
De este modo, el inicio de la minería y la metalurgia andalusí en la depresión de Vera se sitúa en el marco de la tendencia a la recuperación poblacional que tiene lugar durante la fase emiral, y se relaciona con la fundación de nuevos asentamientos, la llegada de las primeras cerámicas vidriadas, y el contacto con, o la presencia de, nuevas poblaciones. La distribución de los restos metalúrgicos parece reflejar una situación en la que conviven pequeños poblados de distinto tipo ("encaramados" y de llanura) que trabajarían la elaboración del mineral, posiblemente para su propio consumo, en combinación con otras actividades productivas, con un núcleo o conjunto de núcleos especializados que producirían para otras necesidades que no fuesen estrictamente las de la propia comunidad, y que, considerando su situación espacial, debieron mantener alguna relación con Bayra, capital del distrito.

\section{Los siglos $\mathrm{X}$ y $\mathbf{X I}{ }^{11}$}

Algunos de estos sitios emirales, como El Picacho, Fuente Álamo, Pago de San Antón II, y el poblado fundado en el siglo $V$ en el Cerro de Montroy, en Villaricos, quedan abandonados antes del inicio de la fase califal. Pero la tendencia a la recuperación poblacional continúa y se afianza en el siglo $X$, debido a la perduración de sitios anteriores $y$, sobre todo, a la fundación de asentamientos nuevos (f. 2).

Perviven ahora el núcleo de Bayra (Pago de San Antón-Cerro del Espíritu Santo) y probablemente el conjunto El Argar-El Cajete, además de algunos asentamientos rurales (Cadímar, Zorreras), y aparecen formas de ocupación del espacio características, concretamente el hisn con alquerías en su entorno. Así, en Sierra Cabrera se levanta el núcleo fortificado de

\footnotetext{
I0. A mediados del siglo XIV, Ibn al-Jațīb (1977:I25-126) afirma de Vera que "su tierra produce abundante cebada que alimenta a las cabalgaduras" y que, en cambio "produce poquísimo trigo."

I I. La consideración conjunta de estos dos siglos se debe, por una parte, a que la cuestión de la perduración de la cerámica datada en el siglo X no siempre está resuelta, y por otra, a la ausencia de referentes claros que permitan discriminar los posibles conjuntos cerámicos del siglo Xl, momento apenas definido arqueológicamente en la zona de estudio a pesar de las circunstancias históricas de ciudades como Murcia o Almería. Las formas cerámicas más características de este momento en la depresión de Vera son los ataifores sin vidriar del tipo M.27.3 de Gutiérrez Lloret (1996), el candil de piquera y cazoleta lenticular con ejemplares similares en el nivel II de Pechina (CASTILLO GALDEANO y MARTÍNEZ MADRID, 1993) y en los niveles superior e inferior de la rábita de Guardamar (AZUAR RUIZ, 1989), y las marmitas a mano o a torneta equiparables morfológicamente a las documentadas en el poblado andalusí de Gatas (FERNANDEZ UGALDE et al., 1999).
} 
Cerro del Inox, próximo al cual aparecen los poblados de Gatas, Ermita de San FranciscoTurre, Alfaix y Las Pilas (f. 2). También se fundan o, mejor, se reocupan poblados en otros valles fluviales, como El Roceipón en el Antas y Terrera Ventura en el Almanzora, valle en el que además aparece el sitio de Cerro Virtud, de probable dedicación minera.

De los antiguos núcleos con indicios de metalurgia parece que sólo El Argar y El Cajete continúan ocupados y desarrollando esta actividad, mientras que en los sitios nuevos los restos de escoria y mineral que se pueden atribuir con seguridad a este momento se han identificado en el Cerro del Inox. La actividad metalúrgica parece seguir focalizada, pues, en la llanura central y en las elevaciones de Sierra Cabrera y, por lo tanto, los cambios en el poblamiento no supondrían cambios en las áreas con indicios de metalurgia, aunque sí en algunos de los asentamientos implicados en la actividad.

Ya hemos visto las características del conjunto El Argar-El Cajete en cuanto a especialización productiva y relación espacial con las minas. Nos detendremos ahora brevemente en el yacimiento del Cerro del Inox.

Se trata en este caso de un asentamiento de altura fortificado emplazado en una elevación escarpada de la vertiente septentrional de Sierra Cabrera (f. 2). Situado a 539 m. s.n.m., su cota es superior a la de todos los demás yacimientos de la depresión.

El hallazgo de ataifores con manchas de manganeso bajo vedrío melado, de morfología y técnica similar a piezas del nivel II de Pechina (CASTILLO GALDEANO y MARTíNEZ MADRID, 1993: f. XVI.7), de repiés bajos con vedrío melado al interior $y$ al exterior, $y$ de marmitas a mano o a torneta próximas a las del poblado andalusí de Gatas autorizan a situar su ocupación entre el siglo $X$ y al menos la primera mitad del siglo siguiente. No se han registrado evidencias de fases posteriores.

En el cerro en el que se ubica se observan en superficie los restos de distintas estructuras arquitectónicas. En la ladera Suroccidental se distingue un recinto formado por un muro transversal a la pendiente con torres cuadrangulares adosadas y dispuestas a intervalos aproximadamente regulares. Al interior de este muro y tanto en esta ladera Suroeste como en la Sur se aprecian las crestas de muros de unos 0,50 m. de espesor, algunos formando ángulo.

En la cima, en el punto más prominente y junto al cortado que cae a pico sobre el barranco de Tremecén, una serie de muros paralelos y perpendiculares entre sí, de unos $0,60 \mathrm{~m}$. de grosor, forman una estructura de planta cuadrangular dos de cuyos lados conservan una longitud de aproximadamente 6 y $6.5 \mathrm{~m}$. Al Sur de este segundo recinto se levantan los restos de un aljibe de unos $8 \mathrm{~m} . \times 2 \mathrm{~m} . \times 2 \mathrm{~m}$. de altura hasta el nivel actual del terreno, excavado en la roca y cerrado en uno de sus extremos por un muro de hormigón (tabiya) de 0,90 m. de espesor. Excepto el aljibe, las partes conservadas de las demás estructuras son de mampostería trabada con argamasa.

El conjunto cubre una superficie de aproximadamente $0,5 \mathrm{Ha}$, que no resulta muy diferente de la de los otros asentamientos de altura contemporáneos, e incluso es inferior a la de algunos de ellos, como el de Gatas (Turre) $(2 \mathrm{Ha})$.

En sus proximidades, sobre elevaciones de la propia sierra o más próximos al cauce del Aguas, se encuentran los yacimientos contemporáneos de Alfaix, Ermita de San FranciscoTurre, Gatas y Las Pilas (f. 2). Excepto algunas noticias para Gatas, desconocemos las estructuras que los integraban. En todo caso, en ninguno de ellos se observan elementos de cierre o fortificación, si bien el topónimo "Turre" sugiere la existencia, en un momento indeterminado -en el yacimiento hay también indicios de ocupación romana-, de alguna construcción defensiva.

En Gatas disponemos de una planta publicada por los hermanos Siret (SIRET y SIRET, 1890: Im. 57) en la que aparecen una serie de estructuras que por su morfología, proporciones y distribución parecen corresponder a vivendas simi- 
lares a las documentadas en otros asentamientos rurales andalusíes ${ }^{12}$.

Las excavaciones recientes proporcionan algunos datos acerca de las actividades productivas que se pudieron llevar a cabo en el asentamiento (FERNÁNDEZ UGALDE et al., 1999). Además de la identificación de un espacio productivo doméstico (cocina), los restos carpológicos apuntan a una agricultura de secano representada por la cebada, y los restos faunísticos, a la combinación de actividades ganaderas, centradas en los ovicápridos, y cinegéticas, documentadas por la presencia de ciervo y cabra montés. Además, su ubicación en la zona hídricamente más favorable de la depresión (HERGET, 1998) y el hallazgo de cerámica andalusí en los aterrazamientos abandonados de la Puerta Azul, situados unos 100 m. al Sur de Gatas (CASTRO et al., 1987), apoyan la práctica de una agricultura de regadío. Por último, el emplazamiento del asentamiento nos aproxima también a un aspecto particularmente relacionado con el tema que nos ocupa.

Desde el punto de vista de la localización relativa a los recursos mineros cartografiados de la cuenca de Vera, el poblado andalusí de Gatas se encuentra a 4,2 km. de fuentes de mineral de hierro. Como hemos expuesto, si consideramos afloramientos de menor envergadura, la proximidad puede ser aún mayor. Una situación parecida se registra en los poblados de Alfaix y Ermita de San Francisco-Turre, situados, respectivamente, a 2,5 y $5 \mathrm{~km}$. de minas de hierro. En ninguno de ellos se han identificado restos de fundición (tabla 2). En general, la mayoría de los asentamientos de la depresión de los que está ausente la escoria se sitúan a una distancia igual o inferior a $5 \mathrm{~km}$. de minas de hierro. En cambio, Cerro del Inox, El Argar y El Cajete, los tres núcleos con metalurgia de este periodo, se encuentran a unos $7 \mathrm{~km}$. de yacimientos cartografiados de este mismo metal. Es decir, los emplazamientos espacialmente más favorables para la minería serían más propios de los asentamientos sin indi- cios de metalurgia que de aquellos en los que se registran desechos de fundición.

\begin{tabular}{l|c|c|c|c} 
Yacimiento & Escoria & Mineral & $\begin{array}{c}\text { Km. } \\
\text { mineral }\end{array}$ & $\begin{array}{c}\text { Cerámica } \\
\text { vidriada }\end{array}$ \\
\hline Alfaix & & & $\leq 5 \mathrm{Fe}$ & $\times$ \\
\hline Cerro del Inox & $\times$ & $\mathrm{Fe}$ & $>5 \mathrm{Fe}$ & $\times$ \\
\hline Cerro Virtud & & & $\leq 5 \mathrm{Fe}, \mathrm{Ag}$ & $\times$ \\
\hline Comara & $(\times)$ & $(\mathrm{Cu}, \mathrm{Fe})$ & $\leq 5 \mathrm{Fe}$ & \\
\hline C. Cadímar & $(\times)$ & & $\leq 5 \mathrm{Fe}$ & $\times$ \\
\hline El Argar & $\times$ & & $>5 \mathrm{Fe}$ & $\times$ \\
\hline El Cajete & $\times$ & $\mathrm{Fe}$ & $>5 \mathrm{Fe}$ & \\
\hline El Roceipón & & & $>5 \mathrm{Fe}$ & \\
\hline Ermita S. Fco. & & & $\leq 5 \mathrm{Fe}$ & \\
\hline Gatas & & & $\leq 5 \mathrm{Fe}$ & $\times$ \\
\hline Las Pilas & $(\times)$ & & $\leq 5 \mathrm{Fe}$ & \\
\hline Loma Rutilla & $(\times)$ & & $>5 \mathrm{Fe}$ & \\
\hline Las Zorreras & & & $>5 \mathrm{Fe}$ & \\
\hline Pago S. Antón & $(\mathrm{x})$ & & $>5 \mathrm{Fe}$ & $\times$ \\
\hline Terrera Ventura & $(\mathrm{x})$ & & $>5 \mathrm{Fe}$ & $\times$
\end{tabular}

Tabla 2: Presencia de escoria, mineral y cerámica vidriada, y distancia a fuentes de materia prima de los asentamientos con fase de los siglos X-XI. Los paréntesis indican yacimientos en los que los restos pueden corresponder a distintas fases de ocupación.

Por una parte esto sugiere que, como hemos visto en el siglo IX en El Argar y El Cajete, en la elección de los emplazamientos de los sitios fundidores pudieron pesar más otras consideraciones que la proximidad a yacimientos de mineral. Las condiciones de los yacimientos del valle del Antas se han examinado en el epígrafe anterior. En cuanto al Cerro del Inox y a los poblados próximos, podemos interpretarlos como un hișn relacionado con una serie de alquerías (Alfaix, Gatas, Ermita de San Francisco-Turre y posiblemente Las Pilas) y probablemente sus respectivos territorios de explotación. Esta ausencia generalizada de una relación espacial definida entre los hușun y las minas se ha observado también en otras zonas de la provincia de Almería (CRESSIER, 1998).

Por otra parte, con la información disponible, la organización social de la producción

12. Como el del Cerro del Castillo de Peñaflor en Jaén (SALVATIERRA y CASTILLO, 1993), Alcaria Longa en el Bajo Alentejo (BOONE, 1994), Villa Vieja en Calasparra (POZO, 1989) o el Castillejo de los Guájares, en Granada (BERTRAND et al., 1990). 
minero-metalúrgica en la zona que nos interesa es por ahora desconocida, ya que faltan evidencias del desarrollo de actividades mineras, por ejemplo, en forma de instrumentos de trabajo. Aun así, si consideramos la relativa proximidad a yacimientos de mineral de los asentamientos de la cuenca del Aguas y la presencia en la zona del centro fundidor del Cerro del Inox, se puede proponer una posible dedicación minera de al menos una parte de la fuerza de trabajo de dichos asentamientos. De acuerdo con sus localizaciones, los poblados de Sierra Cabrera podrían explotar los yacimientos metalíferos de la misma sierra, mientras que Alfaix tendría mejor acceso a los recursos de la Sierra de Bédar.

Ciertamente, esto no excluye que los propios centros transformadores ocupasen también fuerza de trabajo en las labores de extracción, aunque en tal caso las distancias de transporte de la materia prima serían mayores, sobre todo en el centro de la depresión. Algunos aspectos a investigar en relación con esta posible organización serían, además de los espacios productivos y los instrumentos de trabajo presentes en los distintos asentamientos, el volumen de producción de los núcleos metalúrgicos y la procedencia del mineral transformado.

En relación a este último punto, para la zona del Antas disponemos de la información obtenida de una muestra de mineral tomada en superficie en el yacimiento de El Cajete. El análisis de su composición dio como resultado que la roca contenía, además de goetita y hematita, lo que parece algo de calcopirita y cuprita. Si a esto se une la presencia de micas, feldespatos y calcita, se puede proponer, a título de posibilidad, una procedencia de la zona septentrional de la depresión o quizá de sierra Almagrera, en el límite nororiental, al tiempo que parece difícil relacionar la muestra con Herrerías ${ }^{13}$. En consecuencia, al menos una de las áreas de extracción de recursos de El Cajete se encontraría en los criaderos más al Norte de la depresión ${ }^{14}$.
Parece, pues, que entre los periodos califal-taifa se pueden identificar en la depresión de Vera dos áreas en las que tiene lugar la transformación de mineral, posiblemente para la obtención de hierro, cada una con organizaciones y quizá volúmenes de producción distintos. Por una parte, la zona central, con un núcleo o grupo de núcleos especializados, espacialmente relacionados con la capital del distrito y su puerto (MOLINA, 1972: p. 33), que obtenían materia prima de los criaderos de las sierras septentrionales, y quizá también de otras. Por otra, el área de Sierra Cabrera y el río Aguas, con los indicios de fundición centrados en un hisn con distintas funciones, cuyo emplazamiento no parece primar la proximidad a yacimientos de mineral, quizá abastecido de materia prima a través de las alquerías próximas y más favorablemente situadas para el acceso a las minas.

Un último aspecto que queremos tratar es el que se refiere a la repercusión que pudo tener en las comunidades de los siglos $\mathrm{X}-\mathrm{XI}$ de la depresión de Vera su participación o no en las actividades de fundición. $\bigcirc$, en otras palabras, nos interesa saber si el disponer de medios de producción metalúrgica fue un factor determinante de la distancia social entre comunidades, entendida como participación asimétrica de las mismas en la producción y el consumo (CASTRO et al., en prensa).

Tenemos evidencias de que en los poblados andalusíes que nos ocupan se consumieron útiles que, por el trabajo gastado en su elaboración, constituyen objetos con un alto valor social. En el caso de la unidad estructural excavada en Gatas, destacan una aguja o alfiler de cobre o bronce y dos cuchillos de hierro. Sin embargo, el poblado es uno de los que carecen de indicios de metalurgia, lo que indica que estos productos llegarían a él procedentes de otro núcleo. Por lo tanto, la comunidad de Gatas o algunos/as de sus integrantes disponían de sobreproducto con el que participar en las redes de intercambio y acceder a productos con valor de cambio.

13. Agradecemos al Dr. I. Montero el habernos facilitado los resultados del análisis de difracción de rayos X.

14. Hay que recordar, en todo caso, que el mineral podría corresponder también a la fase emiral, durante la cual el asentamiento de Fuente Alamo pudo explotar las vetas de Sierra de Almagro. 
La cerámica vidriada, presente en Gatas y en otros asentamientos contemporáneos de la depresión, es otra categoría de objetos que, por su elaboración y sus patrones de producción (urbana) y distribución (regional o suprarregional), posee estos dos valores.

Esta cerámica se encuentra en ocho de los dieciséis yacimientos registrados de este periodo, siempre en cantidades escasas ${ }^{15}$. Como se observa en la tabla I, el vidriado aparece tanto en asentamientos con escoria como sin ella, y tanto en núcleos situados a más como a menos de $5 \mathrm{~km}$. de yacimientos de mineral. Asimismo, hay casos de yacimientos con escoria de los que la cerámica vidriada está ausente.

En consecuencia, de acuerdo con los datos manejados, en la depresión de Vera en los siglos X-Xl el acceso a los medios de producción metalúrgica no está correlacionado con el acceso a productos importados en los asentamientos. Por lo tanto, podemos plantear que si bien este sector productivo desempeñó un papel económico relevante en la vida de las comunidades de la zona, no influyó de forma decisiva en sus respectivas posiciones dentro de la organización social.

\section{Los últimos siglos medievales}

En un momento que hay que situar a partir de finales del siglo XI o más bien en el XII, probablemente en el marco de inestabilidad política y de presencia militar cristiana en el sudeste de al-Andalus, se registran importantes cambios en el poblamiento de la depresión de Vera.

La gran mayoría de los asentamientos (75\%), entre ellos el hisn de Inox, varias alquerías de la cuenca del Aguas (Alfaix, Gatas, Las Pilas), y los núcleos de El Argar y El Cajete han quedado abandonados. Asimismo, en Vera se despuebla la zona llana del Pago de San Antón, al tiempo que, a juzgar por el material de superficie, se intensifica la ocupación del Cerro del Espíritu Santo.

Esta desaparición de antiguos núcleos, unida a la fundación de una cantidad importante de asentamientos, da lugar a una nueva configuración del poblamiento que parece situarse ya en el siglo XIII, y que se mantiene sin grandes cambios hasta la conquista castellana ${ }^{16}$. En Sierra Cabrera y el Aguas los nuevos núcleos de población tienden a situarse en lugares protegidos y hacia el interior de la sierra (Mojácar La Vieja, Teresa, Cabrera, Cortijo de Gatas, Cortijo del Olivar y Cortijo de la Cerca) (f. 3). En la zona central la población probablemente se concentrase en torno a Bayra-Cerro del Espíritu Santo, mientras que en el Almanzora, en consonancia con su condición de zona de frontera, conocemos establecimientos defensivos como la atalaya nazarí, quizá con un pequeño asentamiento, del Cerro de Montroy (MENASANCH y OLMO, 1994), y la fortificación de Cuevas,

15. Quizá la excavación de nuevos yacimientos introduzca cambios en este planteamiento. En todo caso, el bajo número de ejemplares vidriados, unido a la posibilidad de sustituirlos por otros recipientes que pudiesen desempeñar la misma función, son indicadores de su escaso valor de uso en el contexto de estudio, al tiempo que subrayan el valor de cambio.

16. El establecimiento de las temporalidades de estos asentamientos se ha basado en la presencia de formas y técnicas decorativas como los candiles de pie alto, el esgrafiado, los ataifores de borde triangular y vedrío monocromo o alternado al interior y al exterior, las cazuelas carenadas con asitas o nervaduras verticales, las tinajas estampilladas o el vedrío blanco con motivos al manganeso, con paralelos en Murcia, Lorca, Almería o Málaga (véase nota 4 y ACIÉN ALMANSA, 1986-87). En determinados casos las citas de textos árabes y la información registrada en documentos escritos posteriores a la conquista proporcionan información complementaria.

Los yacimientos que podemos considerar con fiabilidad como ocupados a lo largo de los tres siglos son Cerro de Montroy (Villaricos), Cerro del Espíritu Santo (Vera), y Cabrera y Teresa (Turre). Asimismo, disponemos de información textual y arqueológica relativa a estructuras defensivas en Cuevas del Almanzora (ANUARIO, 1992: p. 7). Junto a éstos, otro grupo de yacimientos se puede fechar como posterior a los siglos XII/XIII, situándolo entre éstos y el siglo XV, aunque sin datos suficientes para afirmar su ocupación continuada. Se trata de Cerro Virtud y Terrera Ventura en Cuevas del Almanzora, y Cadímar, Cortijo El Gitano, Cortijo de Gatas, Cortijo del Olivar y Cortijo de la Cerca en Turre. Por último, la prospección de Mojácar la Vieja, en el valle del Aguas, y la mención de al-Idrīī a 'Aqaba Sāqir (MOLINA, 1972: p. 33) permiten situar el asentamiento en los siglos XII-XIII. Las noticias indirectas aportadas por Ibn al-Jațîb (1977: p. 126) a mediados del siglo XIV sugieren que el sitio pudo quedar abandonado antes de la conquista cristiana, trasladándose su población a la actual Mojácar. En todo caso, hay que señalar la similitud de su conjunto cerámico con los de los yacimientos de Sierra Cabrera. 
en el emplazamiento de la fortaleza de época moderna (ANUARIO, 1992: p. 7) ${ }^{17}$.

En este caso la información relativa a las actividades minero-metalúrgicas procede en su totalidad de hallazgos de superficie, ya que ni el Cerro de Montroy, ni el castillo de Cuevas -los dos sitios con fase nazarí excavados hasta el momento-, han proporcionado datos al respecto, si bien el segundo se encuentra aún poco explorado. De nuevo los indicios consisten en la presencia de rocas de mineral y, sobre todo, de escoria en superficie.

A falta de análisis de las muestras parece que el metal elaborado mayoritariamente era el hierro. En Teresa, además, la presencia de malaquita apunta a una posible explotación de mineral de cobre. En este sentido cabe mencionar que el asentamiento se encuentra a sólo I,3 $\mathrm{km}$. de minas cartografiadas de este metal (IGME, 1981). Por otra parte, hay que recordar que en la elevación minera de Cerro Virtud, en Herrerías, también se detectaron indicios de frecuentación u ocupación a partir del siglo XIII.

Los asentamientos con indicios de fundición se localizan, bien en la zona del Antas, bien en Sierra Cabrera. Se trata, en el primer caso, del Cerro del Espíritu Santo, y en el segundo, de los yacimientos de Cortijo de Gatas, Cabrera y Teresa (f. 3).

El Cerro del Espíritu Santo, situado inmediatamente al Suroeste de la actual población de Vera, se puede identificar con el emplazamiento de la Bayra más reciente, almohade y nazarí. El establecimiento de la frontera entre el reino de Granada y el territorio cristiano en la zona del Almanzora a mediados del siglo XIII determinó que una de sus principales funciones en los siglos sucesivos fuese la militar. De ella dan cuenta numerosas referencias textuales (véase TAPIA, 1986 y 1987), así como los restos de sus estructuras defensivas (CARA y ORTIZ, 1997).
Desde el punto de vista de las actividades económicas, los textos relativos a la Vera nazarí refieren de forma directa o indirecta la existencia de huertas (TAPIA, 1986: passim) y el cultivo de cereal -sobre todo cebada y algo de trigo-, la práctica de la ganadería -cría de camellos- $y$, sobre todo, el desarrollo de actividades comerciales, a las que parece que se dedicaba buena parte de la población (IBN AL-JATIB, 1977: 125- 126; BOSCH-VILA y HOENERBACH, 1983: p. 58). A esto hay que añadir ahora la fundición, atestiguada por la presencia de escoria.

En Sierra Cabrera, el yacimiento del Cortijo de Gatas consiste en un recinto situado en la plataforma superior de un cerro desde el que se domina el valle del Aguas y la llanura central de la depresión. Está formado por un muro que parece seguir el perímetro de la cima y otra estructura de planta indeterminada. $\mathrm{Ni}$ en su interior ni en las laderas de la elevación se distinguen otros restos de construcciones. El conjunto cerámico de superficie (jarritas de pasta pajiza con repié, fragmentos con decoración esgrafiada, alcadafes troncocónicos con labio engrosado al exterior, fragmentos vidriados en verde al interior y melado al exterior, al estilo de piezas de Lorca o Murcia, o en blanco al interior y al exterior) se sitúa en época tardía, sin que se registren indicios de ocupaciones anteriores, y es escaso y poco denso. El sitio parece corresponder a una edificación defensiva sin poblado asociado, que acogería a una pequeña guarnición.

Más hacia el interior del macizo se encuentran los otros dos yacimientos con indicios de fundición. Se trata de Cabrera y Teresa, importantes despoblados moriscos con abundantes menciones en la documentación escrita posterior a la conquista (TAPIA, 1986b; GRIMA, 1987).

En ambos casos los asentamientos están situados sobre elevaciones escarpadas en cuyas cimas se levantan estructuras de fortificación.

17. En la zona central, además, hay que situar la alquería de Antas, mencionada por al-Idrīīi (1989: 253), en la que se refugian parte de los huidos de Vera inmediatamente antes de la capitulación de la ciudad en I488 (TAPIA, 1986b: p. 462). En cuanto al valle del Almanzora, el poblamiento está infrarrepresentado en el registro arqueológico, como muestran los datos del Repartimiento de Cuevas (CASTRO et al., 1994). 
En Cabrera los vestigios visibles permiten identificar un muro de cierre y una torre de planta cuadrangular, y en Teresa, los restos de un lienzo de muro con construcciones cuadrangulares distribuidas a tramos aproximadamente regulares. Cabrera contaba además con dos aljibes, uno en la cima y otro en la ladera Sur. Las construcciones defensivas dominaban el área del caserío, que se extendía por las laderas preferentemente meridionales. En estas zonas extramuros fue donde se localizaron las concentraciones de escoria.

A tenor de los hallazgos de superficie, el volumen de producción de metal de cada uno de los núcleos fundidores de la depresión debió ser más bien limitado. En este sentido, para el caso de Bayra-Cerro del Espíritu Santo un inventario de bienes de propios poco posterior a la conquista registra el almudí para el peso de la harina, un molino, una carnicería y varias tiendas (GRIMA, 1987: 175), y, en cambio, no hace mención a la existencia de herrerías, como cabría esperar en caso de tratarse de una actividad destacada. Sin embargo, si consideramos los asentamientos en su conjunto, los lugares con escoria representan alrededor de un tercio del total de sitios registrados. Esta proporción probablemente fuese mayor en Sierra Cabrera, donde de los cinco sitios conocidos arqueológicamente, en tres se identificó la presencia de mineral y/o restos de fundición.

Estos tres poblados -Cortijo de Gatas, Cabrera y Teresa- se sitúan respectivamente a 5 , 6 y $7 \mathrm{~km}$. de las minas de hierro cartografiadas más próximas. Por su parte, los asentamientos de la misma sierra sin indicios de metalurgia se encuentran todavía más alejados de esos recursos (tabla 3). Esto indica para esta zona una relación débil entre patrón de asentamiento y distancias de aprovisionamiento de mineral. Como, además, la fundición se encuentra relativamente dispersa entre varios asentamientos aparentemente sin grandes volúmenes de producción, cabe plantear que estos núcleos se autoabasteciesen de materia prima probablemente a partir de afloramientos menores más próximos.

\begin{tabular}{l|c|c|c} 
Yacimiento & Escoria & Mineral & Km. mineral \\
\hline Cabrera & $\times$ & $\mathrm{Fe}$ & $>5 \mathrm{Fe}$ \\
\hline Castillo de Cuevas & & & $\leq 5 \mathrm{Fe}$ \\
\hline Cerro E. Santo & $\times$ & & $>5 \mathrm{Fe}$ \\
\hline Cerro de Montroy & & & $>5 \mathrm{Fe}$ \\
\hline Cerro Virtud & & & $\leq 5 \mathrm{~Pb}, \mathrm{Ag}$ \\
\hline Cortijo Cadímar & $(\times)$ & & $\leq 5 \mathrm{Fe}$ \\
\hline Cortijo de Gatas & $\times$ & & $\leq 5 \mathrm{Fe}$ \\
\hline Cortijo de la Cerca & & & $>5 \mathrm{Fe}$ \\
\hline Cortijo del Olivar & & & $>5 \mathrm{Fe}$ \\
\hline Cortijo El Gitano & & $\mathrm{Fe}$ & $\leq 5 \mathrm{Fe}$ \\
\hline Mojácar la Vieja & & & $\leq 5 \mathrm{Fe}$ \\
\hline Teresa & $\times$ & $\mathrm{Cu}$ & $>5 \mathrm{Fe}, \leq 5 \mathrm{Cu}$ \\
\hline Terrera Ventura & $(\times)$ & & $>5 \mathrm{Fe}$
\end{tabular}

Tabla 3: Presencia de escoria y mineral y distancia a fuentes de materia prima de los asentamientos con fase de los siglos XIII-XV. Los paréntesis indican yacimientos en los que los restos pueden corresponder a distintas fases de ocupación.

A partir del siglo XIII, pues, parece que la zona central de la depresión ha perdido su carácter de centro metalúrgico, y ahora en ella la fundición se lleva a cabo de forma más limitada en Bayra, centro político-administrativo y enclave comercial. En Sierra Cabrera, en cambio, se ha multiplicado el número de asentamientos con huellas de producción metalúrgica. Su patrón espacial no ofrece una relación inequívoca con los principales recursos de mineral de hierro, y los poblados parecen más bien centros a pequeña escala autoabastecidos de materia prima a partir de fuentes superficiales próximas. Tomados en su conjunto, sin embargo, permiten caracterizar a la Sierra Cabrera nazarí como un área metalúrgica, aunque no especializada, cuya producción pudo destinarse al menos en parte al intercambio y a su consumo fuera de la zona productora.

En este sentido, los datos de las fuentes escritas relativas al medio y bajo Aguas, para la que contamos con los Libros de Repartimiento de Teresa y Turre, muestran que a finales del siglo XV en las tierras de la población de Teresa se cultivaban alrededor de 140 moreras y 430 olivos, además de otros productos 
(488 almendros, 204 higueras y un peral). En cuanto a la actual Turre, con la cual estaría relacionado el conjunto de población de los yacimientos de El Gitano y Cadímar, la documentación registra 1.100 moreras y 1.500 olivos (CASTRO et al., 1994).

Las moreras son una clara producción excedentaria dirigida a la obtención de seda en espacios situados fuera de la depresión. Por otra parte, a la vista de las poblaciones (alrededor de 600 habitantes por núcleo habitado en la cuenca del Aguas), el número de olivos sugiere que la producción de aceite debía rebasar las necesidades locales. Por lo tanto, nos encontramos ante unidades de producción diversificadas en las que se simultaneaban cultivos de huerta, secano extensivo y cultivos arbóreos para una producción que, rebasando las necesidades subsistenciales, iría dirigida a su comercialización en mercados exteriores. En este marco hay que situar el desarrollo de la transformación de mineral por parte de estas comunidades, al margen de cuál fuese su volumen de producción.

\section{CONCLUSIÓN}

A diferencia de lo que se ha observado en el área relativamente próxima de Guadix (BERTRAND et al., 1996), donde la minería emiral se identifica como continuadora de la visigoda, en la depresión de Vera las actividades minerometalúrgicas se reemprenden o, cuando menos, se intensifican a partir del siglo IX, precisamente cuando se produce el asentamiento de nuevas poblaciones árabes y norteafricanas.

Su importancia para la economía de la región resulta difícil de evaluar, ya que no disponemos de datos que permitan algún tipo de cuantificación en relación a otras actividades productivas. Los datos espaciales muestran que en la elección de los emplazamientos de los sitios metalúrgicos la proximidad a los recursos de mineral no fue un criterio de primer orden. Más bien parecen primar otras consideraciones, como posiblemente la defensa en el asentamiento emiral de El Picacho, la proximidad al núcleo de Bayra o incluso un mejor acceso al mar en el caso de El Argar-El Cajete, o la disposición de recursos hídricos abundantes y la organización de territorios agrarios en los asentamientos de Sierra Cabrera, entre los que se cuentan los sitios fortificados de Inox, Teresa y Cabrera. Sin embargo, también hay que considerar la existencia de un centro metalúrgico especializado como el de El Argar-El Cajete en los siglos IX-X o incluso $X I$, o el volumen de producción que pudo representar el funcionamiento simultáneo de los poblados fundidores nazaríes, que suponen un papel importante de la minería y la metalurgia dentro de la economía de la región.

La organización de estas actividades en nuestra zona de estudio presenta características diferentes en las distintas fases andalusíes, lo cual concuerda con el planteamiento de Cressier (1998) para la provincia de Almería, que sostiene la diversidad organizativa de la minería andalusí en el tiempo y en el espacio en función de factores como los metales explotados o el marco cronológico. Con los límites que impone la procedencia del material con que contamos, podemos plantear que en la fase emiral una parte de la transformación del mineral se encontraría concentrada en el conjunto especializado de El Argar-El Cajete, mientras que otra se produciría en diferentes asentamientos menores no especializados.

Distintas organizaciones, y probablemente volúmenes de producción, los encontramos también en los siglos $X-X \mid$. En ese momento la fundición se relaciona, por una parte, con el mencionado núcleo especializado situado en el centro de la depresión, y por otro, con el "distrito" de Sierra Cabrera a través de su presencia en el hișn de Inox. En la zona de Cabrera, la distribución espacial de los yacimientos en relación a los recursos de mineral y la de la escoria en los asentamientos sugiere la explotación y aportación de materia prima por parte de las comunidades de las alquerías, la transformación de la misma en el hișn, y posiblemente el retorno a las primeras de productos elaborados en un circuito de autobastecimiento. En el caso de El Argar-El Cajete nos encontramos con un núcleo especializado en la fundición y, sin embargo, emplazado en la posición 
espacialmente más desfavorable para el acceso a minas, con lo que esto podía suponer en cuanto a fuerza de trabajo y costes de transporte de la materia prima, pero, al mismo tiempo, equidistante de las distintas áreas-fuente potenciales al Norte, Oeste y Sur del asentamiento. Su emplazamiento parece primar la proximidad a la capital del distrito y a su posible puerto y, por lo tanto, un mejor acceso a los mercados.

Entre los siglos XIII y XV participan en las actividades metalúrgicas el centro político-administrativo de Bayra, el probable enclave militar del Cortijo de Gatas, y los husun con poblado de Teresa y Cabrera, donde los indicios de fundición se localizan en el área ocupada por el caserío. En los tres últimos consideramos la posibilidad de un autoabastecimiento de materia prima a partir de pequeños filones próximos, dados sus presumiblemente limitados volúmenes de producción y su relativo alejamiento de las minas. Bayra y posiblemente el Cortijo de Gatas pudieron producir para su propio consumo, mientras que la producción de Sierra Cabrera considerada en su conjunto pudo rebasar las necesidades locales.

Una cuestión fundamental es qué grupo o grupos sociales tenían el control sobre estas producciones. En determinados casos, como los pequeños poblados emirales abiertos y diversificados, se puede pensar en comunidades que organizan sus producciones de objetos, entre ellas la metalúrgica, de forma autónoma. Y lo mismo se podría decir del hisn de Inox, si, como se plantea para otras zonas del Sur de al-Andalus, y en concreto para la actual provincia de Almería, se verifica que su origen y funcionamiento están vinculados a la organización y protección de las comunidades de las alquerías próximas y sus territorios agrarios. Más difícil es formular una hipótesis social en relación a El Argar-El Cajete en tanto no contemos con información más detallada acerca de las fases de ocupación y sus características. En todo caso, los patrones de consumo de la cerámica vidriada en relación con la fundición indican que en nuestra zona de estudio en los siglos X-XI, quien tuviese el control de la transformación del mineral de hierro no incidía de forma decisiva en la capacidad de consumo de determinados productos importados. Esto significa que el equilibrio, o la simetría, entre producción y consumo de las distintas comunidades no se vio afectado por el desarrollo de la metalurgia. En consecuencia, ésta desempeñó un papel importante en la esfera económica de estos grupos, pero no en la socio-política.

En el periodo nazarí parece que podemos hablar de distintas situaciones. Los poblados fundidores de Teresa y Cabrera presentan similitudes morfológicas con el asentamiento metalúrgico almohade-nazarí del Cerro Castellón de Gérgal, con una fortificación en la zona más elevada, dominando el caserío, y con los restos de fundición extramuros. Cressier (1998), basándose en estas características, plantea la posibilidad de un control exterior sobre la población productora de metal. En Sierra Cabrera, sin embargo, no se trata de núcleos propiamente minero-metalúrgicos, sino sobre todo de poblados agrícolas en los que, además, se llevó a cabo la transformación del mineral. En todo caso, en el contexto de la sierra estos núcleos parecen centralizar las actividades de fundición, ya que en los sitios de menor tamaño y sin fortificación del Cortijo de la Cerca y el Cortijo del Olivar, muy próximos y contemporáneos a Cabrera (fig. 3), no se detectan indicios de su desarrollo. Junto a ellos, en la fortificación del Cortijo de Gatas posiblemente se ubicase una pequeña herrería, o incluso una forja relacionada con la función defensiva del asentamiento y con las necesidades de su guarnición. Y, por último, en Bayra-Cerro del Espíritu Santo podemos plantear el funcionamiento de pequeños establecimientos transformadores quizá controlados por los propios artesanos. 


\section{BIBLIOGRAFIA}

'ABD AL-KARIM, G. (1974): "La España musulmana en la obra de Yāqūt (ss. XII-XIII). Repertorio enciclopédico de ciudades, castillos y lugares de al-Andalus extraido del Mu'ŷam al-buldān (Diccionario de los países)", Cuadernos de Historia del Islam. VI. pp. I25-138.

ACIÉN ALMANSA, M. (1986-87): "La céramica medieval del Teatro Romano de Málaga", Mainake. VIII-IX. pp. 229-234.

ACIÉN ALMANSA, M.; CASTILLO GALDEANO, F.; FERNÁNDEZ GUIRADO, Ma R.; PERAL BEJARANO, C.y VALLEJO TRIANO, A. ( 1995): "Evolución de los tipos cerámicos en el S.E. de Al-Andalus", Actes du $5^{\text {ème }}$ colloque sur la céramique médiévale en Méditerranée occidentale. Rabat, pp. 125-139.

ACIÉN ALMANSA, M. y MARTÍNEZ MADRID, R. (1989): "Cerámica islámica arcaica del sudeste de al-Andalus". Boletín de Arqueología Medieval. 3. pp. 123-135.

ALMERÍA (1993): Vivir en al-Andalus. Exposición de cerámica (S. IX-XV). Almería.

ANUARIO (1992): "Memoria de gestión año 1992. Provincia de Almería”. Anuario Arqueológico de Andalucía. Vol. I. pp. 5-7.

AZUAR RUIZ, R. (1989): La rábita califal de Guardamar del Segura (Alicante): cerámica, fauna, malacofauna y epigrafía. Alicante.

BERNABÉ GUILLAMÓN, M. y LÓPEZ MARTÍNEZ, J.D. (1993): El palacio islámico de la Calle Fuensanta, Murcia. Murcia.

BERTRAND, M.; CRESSIER, P.; MALPICA CUELLO, A. y ROSSELLÓ BORDOY, G. (1990): "La vivienda rural medieval de "El Castillejo" (Los Guájares, Granada)", La casa hispano-musulmana. Aportaciones de la arqueología. Granada, pp. 207-227.

BERTRAND, M.; SÁNCHEZ VICIANA, J.R. y ZUBIAUR MARCOS, J.F. (1996): "Mines et métallurgies médiévales de la Sierra Nevada (Région de Guadix, Prov. de Grenade). Premières données", Actas de las I Jornadas sobre minería y tecnología en la Edad Media peninsular. León, pp. 180-197.

BOONE, J.L. ( 1994): "Rural settlement and islamization in the Lower Alentejo of Portugal. Evidence from Alcaria Longa", en Campos, J.M.; Pérez, J.A. y Gómez, F. (eds.): Arqueología en el entorno del Bajo Guadiana. Actas del Encuentro Internacional de Arqueología del Suroeste. Huelva, pp. 527-544.

BOSCH-VILA, J. y HOENERBACH, W. ( 1 983): "Un viaje oficial de la corte nazarí (1 347)", Andalucía islámica. Textos y estudios. II-III. Anejos de Cuadernos de Historia del Islam. pp. 33-69.

CANO PIEDRA, C. (1990): "Estudio sistemático de la cerámica de Madinnat Ilbīra”, Cuadernos de la Alhambra. 26. pp. 25-89.
CARA BARRIONUEVO, L. y RODRÍGUEZ LÓPEZ, J. $M^{a}$ (1986): "Notas para el estudio de la minería almeriense anterior al siglo XIX". Boletín del Instituto de Estudios Almerienses. 6 (Letras). Almería, pp. I I-24.

CARA BARRIONUEVO, L. y ORTIZ SOLER, D. ( 1977 ): "Un modelo de ciudad fronteriza nasrí: urbanismo y sistema defensivo de Vera". Actas del Congreso La frontera oriental nazarí como sujeto histórico. Lorca-Vera, 22-24 de Noviembre de 1994. Almería. pp. 3 1 |-327.

CARULLA, N. (1987): "Análisis geológico del territorio doméstico y del área de captación de Gatas", en Chapman, R.; Lull, V.; Picazo, M. y Sanahuja, Ma E. (eds.): Proyecto Gatas. Sociedad y economía en el sudeste de España c. 2500-800 a.n.e. I. La prospección arqueoecológica. B.A.R. Int. ser., 348. Oxford, pp.| 32-152.

CASTILLO GALDEANO, F. y MARTÍNEZ MADRID, R. 1993: "Producciones cerámicas en Bayyana", en Malpica Cuello, A. (ed.): La cerámica altomedieval en el Sur de alAndalus. Primer encuentro de arqueología y patrimonio. Granada, pp. 67-116

CASTRO, P: CHAPMAN, R.W: GONZALEZ MARCEN, P.; LULL, V.; PICAZO, M..; RISCH, R. y SANAHUJA, Ma E. ( 1987): "Proyecto Gatas (Turre, Almería). Tercera campaña 1987", Anuario Arqueològico de Andalucía. Vol. II. pp. $225-231$.

CASTRO, P.; COLOMER, E.; COURTY, M.A.; FEDEROFF, N.; GILI, S.; GONZÁLEZ MARCÉN, P.; JONES, M.K.; LULL, V.; MCGLADE, J.; MICÓ, R.; MONTÓN, S.; RIHUETE, C.; RISCH, R.; RUIZ PARRA, M.; SANAHUJA, M.E. y TENAS, M. (eds.) (1994): Temporalities and desertification in the Vera Basin, south east Spain. Archaeomedes Project, Vol. 2, DGXII, Bruselas.

CASTRO, P;; CHAPMAN, R.W.; GILI, S.; LULL, V.; MICÓ, R.; RIHUETE, C.; RISCH, R. y SANAHUJA, Ma E. (eds.) (1998): Aguas Project. Palaeoclimatic reconstruction and the dynamics of human settlement and land-use in the area of the middle Aguas (Almería), in the south-east of the Iberian Peninsula, Luxemburgo.

CASTRO, P.; GILI, S.; LULL, V.; MICO, R.; RIHUETE, C.; RISCH, R. y SANAHUJA, Ma E. (en prensa): "Teoría de la producción de la vida social. Un análisis de los mecanismos de explotación en el sudeste peninsular (3000I 550 cal ANE)", I Congreso de Arqueología social. La Rábida, Huelva.

CRESSIER, P. (1998): "Observaciones sobre fortificación y minería en la Almería islámica”, en MALPICA, A. (ed.): Castillos y territorio en al-Andalus: Granada, pp. 470-496.

CRESSIER, P.; FLORES ESCOBOSA, I.; POZO MARÍN R. y RUEDA CRUZ, Ma I. (en prensa): "La céramique médiévale", en Schubart, H.; Pingel, V. y Arteaga, O.: Fuente Alamo. Band I. Madrid.

ESCUDERO ARANDA, J. (1988-90): "La cerámica decorada en "verde y manganeso" de Madinat al-Zahra", Cuadernos de Madinat al-Zahra. 2. pp. |27-|6I. 
FERNÁNDEZ UGALDE, A.; MENASANCH DE TOBARUELA, M. y PRESAS VIAS, M. (1999): "El asentamiento andalusí de Gatas", en Castro, P.; Chapman, R.; Gili, S.; Lull, V.; Micó, R; Rihuete, C.; Risch, R. y Sanahuja, M.E. (eds): Proyecto Gatas 2. La dinámica arqueológica de la ocupación prehistórica. Sevilla, pp. 394-4II.

GRIMA CERVANTES, J. A. (1987): La Tierra de Mojácar y la comarca del río Aguas: desde su conquista por los Reyes Católicos hasta la conversión de los mudéjares, I 488-1500. Mojácar.

GUTIÉRREZ LLORET, S. (1996): La Cora de Tudmir de la antigüedad tardía al mundo islámico. Madrid.

HERGET, W. (1998): "Hydrological regime and water exploitation", en Castro et al. (eds.). pp. 52-61.

HOFFMAN, G. (1988): Holozänstratigraphie und Kustenlinienverlagerung an der Andalusischen Mittelmeerküste. Bremen.

IBN AL-JATIB ( 1977): Mi'yār al-ijtiyār fĩ diikr al-ma'āhid waI-diyār. Texto árabe, traducción y estudio por Dr. Mohamed Kamal Chabana. Rabat.

IDRĪSĪ (1974): Geografía de España. Prólogo por A. Ubieto Arteta. Textos medievales. 37. Valencia.

IGME (1981): Revisión del mapa metalogenético. Hoja N. 84-85 Almería-Garrucha del M.T.N. a escala 1:200.000. Memoria. Madrid.

MENASANCH DE TOBARUELA, M. (en prensa): "Un espacio rural en territorio bizantino: análisis arqueológico de la depresión de Vera entre los siglos $\vee$ y VII", V Reunión de Arqueología Paleocristiana Hispánica. Cartagena, 16-19 de abril 1998

MENASANCH DE TOBARUELA, M. y OLMO ENCISO, L. (|99|): "El poblamiento tardorromano y altomedieval en la cuenca baja del río Almanzora (Almería). Cerro de Montroy (Villaricos, Cuevas del Almanzora): campaña de excavación 199|", Anuario Arqueológico de Andalucía.. Vol. II. pp. 28-35.

MENASANCH DE TOBARUELA, M. y OLMO ENCISO, L. (1994): "Cerro de Montroy (Villaricos, Cuevas del Almanzora). Las campañas de excavación 1983, 1986 y 199|". Anexo a Castro et al. (eds.).
MOLINA, E. (1972): "La cora de Tudmīr según al-'Udrī (siglo XI): Aportaciones al estudio geográfico-descriptivo del SE peninsular", Cuadernos de Historia del Islam. Serie monográfica - Islámica occidentalia. 3.

MUÑOZ MARTÍN, Ma M. y DOMÍNGUEZ BEDMAR, M. (1984): "Cerámica hispano-musulmana del Cerro del Castillo (Albox, Almería)", Roel. 5. pp. 3-68.

NAVARRO PALAZÓN, J. (1986): La cerámica islámica en Murcia. Vol. I: Catálogo. Murcia.

NAVARRO PALAZÓN, J. (1990): "Los talleres islámicos de San Nicolás de Murcia. Memoria preliminar", Fours de potiers et "testares" médiévaux en Méditerranée Occidentale. Madrid, pp. 26-43.

POZO, I. ( 1 989): "El despoblado islámico de "Villa Vieja", Calasparra (Murcia). Memoria preliminar", Miscelánea Medieval Murciana. XXV. pp. 185-212.

POZO MARÍN, R. y RUEDA CRUZ, I.Ma 1993: "El Argar 1991: cerámica islámica", Anuario Arqueológico de Andalucía. Vol. II. Sevilla, pp. 7I-72.

SALVATIERRA CUENCA, $\vee$. y CASTILLO ARMENTEROS, J.C. (1993): "Il campaña de excavaciones en el yacimiento medieval del Cerro del Castillo de Peñaflor (laén)", Anuario Arqueológico de Andalucía. Vol. II. pp. 312-318.

SCHUBART, H. (1993): "El Argar: Vorbericht über die Probegrabung 199I", Madrider Mitteilungen. 34. Madrid, pp. |3-2|.

SIRET, L. (1906): Villaricos y Herrerías. Antigüedades púnicas, romanas, visigóticas y árabes. Madrid.

SIRET, H. y SIRET, L. (I890): Las primeras edades del metal en el sudeste de España. Barcelona.

TAPIA GARRIDO, I.A. (I986a): Almería musulmana I. (7| I- I I72). Historia General de Almería y su provincia. Vol. 3. Almería.

TAPIA GARRIDO, I.A. (1986b): Almería musulmana II. ( I 172-1492). Historia General de Almería y su provincia. Vol. 4. Almería.

TAPIA GARRIDO, J.A. (1987): Historia de la Vera antigua. Almería. 


\section{RESUMEN}

A partir de los datos obtenidos en recientes trabajos de excavación y prospección en la depresión de Vera (Almería) por diferentes equipos de investigación, ésta aparece como una zona extractora y fundidora de mineral desde el periodo emiral hasta el nazarí. Las actividades minero-metalúrgicas parecen dirigidas de forma dominante a la obtención de hierro.

Con el presente trabajo pretendemos dar a conocer datos inéditos y recopilar otros ya publicados, con el fin de ofrecer una hipótesis de organización socioeconómica de esta actividad en el área estudiada y acercarnos a su repercusión en las comunidades andalusíes a lo largo del tiempo.

\section{PALABRAS CLAVE}

Minería, metalurgia, periodo andalusí, sudeste de la península Ibérica.

\section{ABSTRACT}

According to data provided by recent excavations and field surveys carried out in the Vera Basin (Almería) by different research teams, this region appears as an important area of extraction and smelting of metal ores from the Emiral until the Nazarine period. Mining and metallurgical activities mainly seem to have focused on the production of iron.

The present study presents unpublished data and compiles a range of previously existing information, in order to offer a hypothesis on the socioeconomic organisation of this activity in the study area and to approach an understanding of its effects on communities in the region during the Andalusian period.

\section{KEY WORDS}

Mining, metallurgy, Andalusian period, Southeast Iberia. 


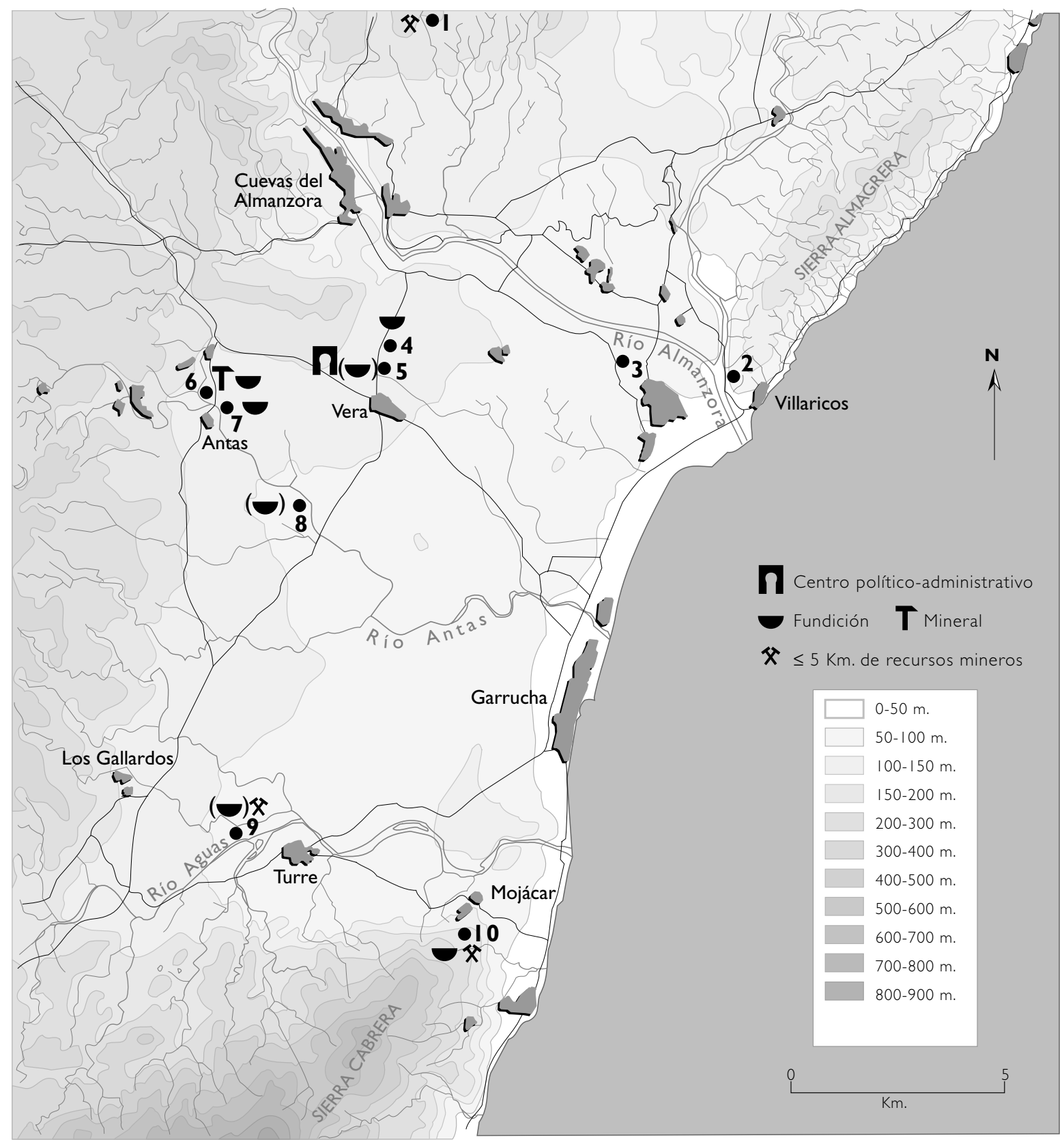

Fig. I. Asentamientos e indicios de actividad minero-metalúrgica durante el siglo IX.

I: Fuente Álamo

2: Cerro de Montroy

3: Las Zorreras

4: Pago de San Antón II

5: Pago de San Antón

6: El Cajete

7: El Argar

8: Loma Rutilla

9: Cortijo Cadímar

10: El Picacho

(Los paréntesis indican yacimientos con varias fases de ocupación) 


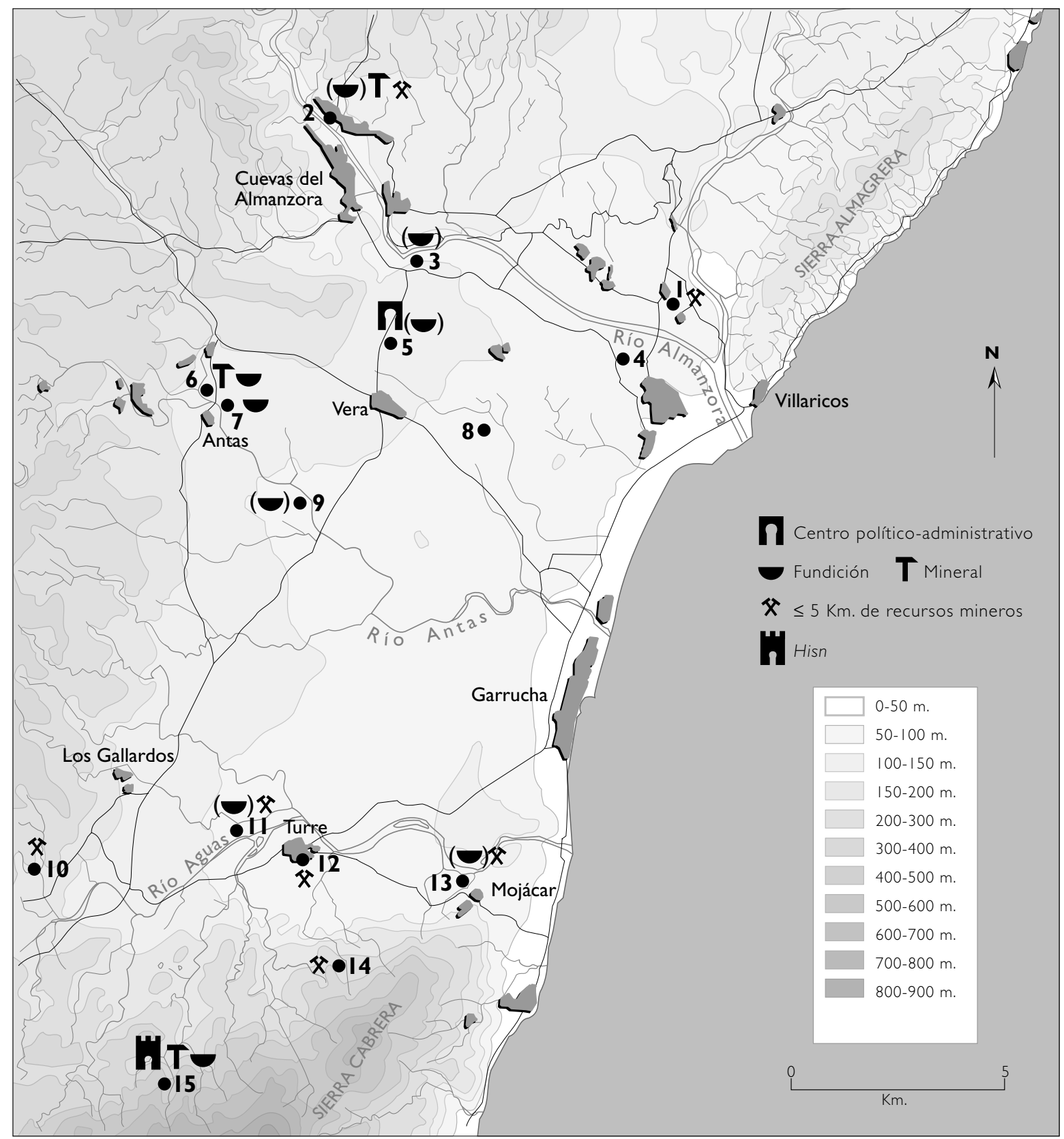

Fig. 2. Asentamientos e indicios de actividad minero-metalúrgica durante los siglos X-XI.

I: Cerro Virtud

2: Comara

3: Terrera Ventura

4: Las Zorreras

5: Pago de San Antón

6: El Cajete

7: El Argar

8: El Roceipón

(Los paréntesis indican yacimientos con varias fases de ocupación.)
9: Loma Rutilla

10: Alfaix

I 1: Cortijo Cadímar

12: Ermita de San Francisco

13: Las Pilas

14: Gatas

15: Cerro del Inox

Centro político-administrativo

$\boldsymbol{X} \leq 5 \mathrm{Km}$. de recursos mineros Hisn 


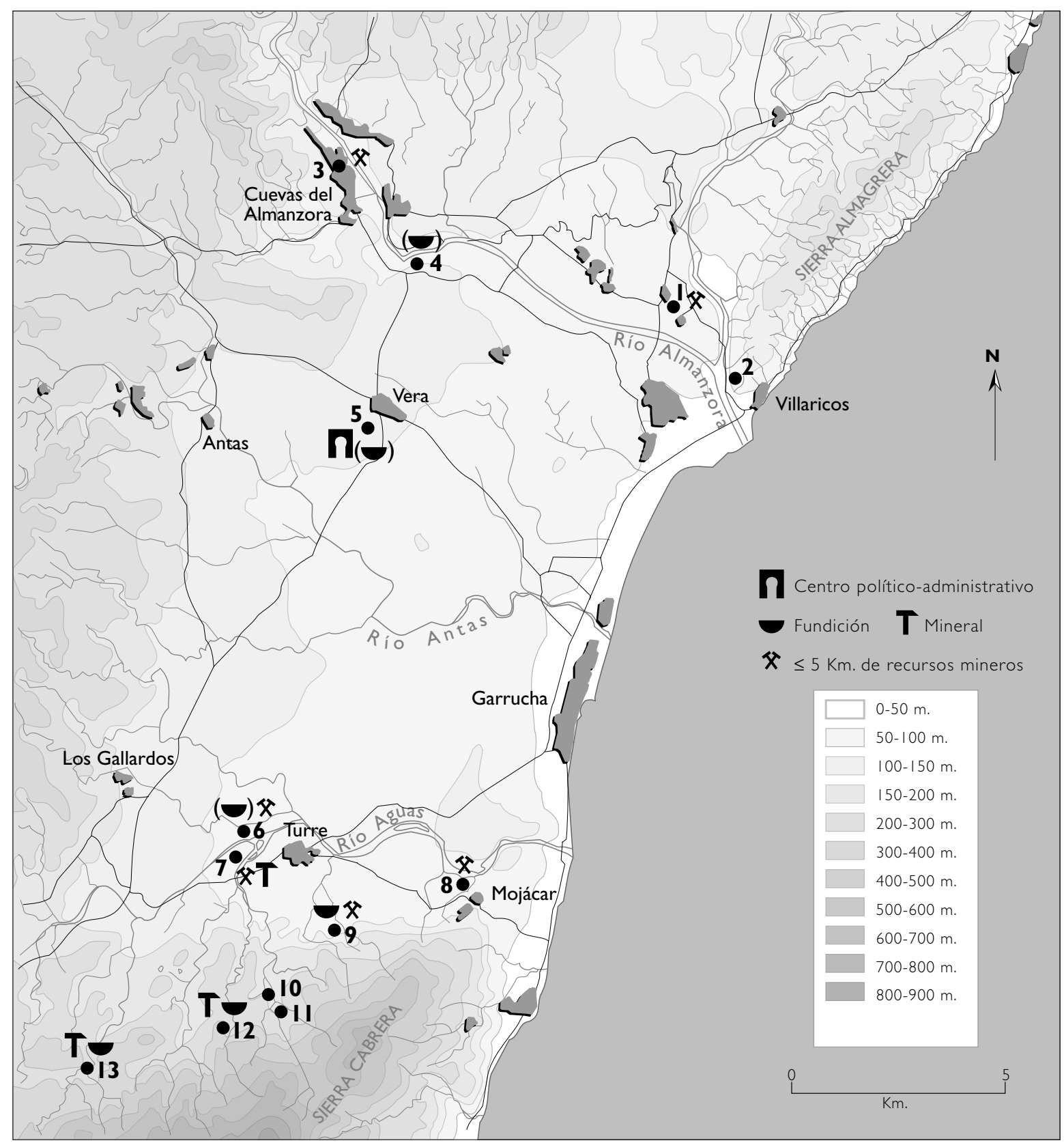

Fig. 3. Asentamientos e indicios de actividad minero-metalúrgica durante los siglos XIII-XV:
I: Cerro Virtud
2: Cerro de Montroy
8: Mojácar La Vieja
3: Castillo de Cuevas
9: Cortijo de Gatas
4: Terrera Ventura
10: Cortijo de la Cerca
5: Cerro del Espíritu Santo
I I: Cortijo del Olivar
6: Cortijo Cadímar
12: Cabrera
7: Cortijo El Gitano
13: Teresa.

(Los paréntesis indican yacimientos con varias fases de ocupación) 